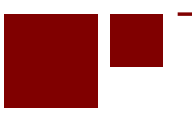

C E N T E R for RETIREMENT RE S E A R C H at BOSTON COLLEGE

\title{
THE RELATIONSHIP BETWEEN OCCUPATIONAL REQUIREMENTS AND SSDI ACTIVITY
}

\author{
Matthew S. Rutledge, Alice Zulkarnain, and Sara Ellen King
}

CRR WP 2019-5

February 2019

\author{
Center for Retirement Research at Boston College \\ Hovey House \\ 140 Commonwealth Avenue \\ Chestnut Hill, MA 02467
}

Tel: 617-552-1762 Fax: 617-552-0191

http://crr.bc.edu

Matthew S. Rutledge is an associate professor of the practice of economics at Boston College and a research fellow at the Center for Retirement Research at Boston College (CRR). Alice Zulkarnain is a research economist at the CRR. Sara Ellen King is a research associate at the CRR. This research was supported by the U.S. Social Security Administration (SSA) through grant \#5 DRC12000002-06 to the National Bureau of Economic Research (NBER) as part of the SSA Disability Research Consortium. The opinions and conclusions expressed are solely those of the authors and do not represent the opinions or policy of SSA, any agency of the federal government, the NBER, or Boston College. Neither the United States Government nor any agency thereof, nor any of their employees, makes any warranty, express or implied, or assumes any legal liability or responsibility for the accuracy, completeness, or usefulness of the contents of this report. Reference herein to any specific commercial product, process or service by trade name, trademark, manufacturer, or otherwise does not necessarily constitute or imply endorsement, recommendation or favoring by the United States Government or any agency thereof.

(C) 2019, Matthew S. Rutledge, Alice Zulkarnain, and Sara Ellen King. All rights reserved. Short sections of text, not to exceed two paragraphs, may be quoted without explicit permission provided that full credit, including $(\mathcal{C}$ notice, is given to the source. 


\begin{abstract}
About the Center for Retirement Research
The Center for Retirement Research at Boston College, part of a consortium that includes parallel centers at the National Bureau of Economic Research, the University of Michigan, and the University of Wisconsin-Madison, was established in 1998 through a grant from the U.S. Social Security Administration. The Center's mission is to produce first-class research and forge a strong link between the academic community and decision-makers in the public and private sectors around an issue of critical importance to the nation's future. To achieve this mission, the Center sponsors a wide variety of research projects, transmits new findings to a broad audience, trains new scholars, and broadens access to valuable data sources.
\end{abstract}

Center for Retirement Research at Boston College

Hovey House

140 Commonwealth Ave

Chestnut Hill, MA 02467

Tel: 617-552-1762 Fax: 617-552-0191

http://crr.bc.edu

Affiliated Institutions:

The Brookings Institution

Mathematica - Center for Studying Disability Policy

Syracuse University

Urban Institute 


\begin{abstract}
Evaluations of Social Security Disability Insurance (SSDI) applications are based not just on poor health, but in most cases consider the vocational factors of age, education and work experience to determine whether individuals can work. These criteria indicate that SSDI applicants must not only be in poor health, but in poor health that actually conflicts with the requirements of their occupation (and other occupations). Yet little is known about the relationship between SSDI activity and the ability to meet occupational requirements. This study devises a Health Mismatch Index, which is the share of workers in an occupation citing healthrelated difficulties in the Survey of Income and Program Participation that would prevent them from performing at least one requirement marked as essential for their occupation in the Occupational Requirement Survey.

The results show that the most common difficulties in required abilities that result in health mismatch are lifting 25 lbs., standing for one hour, or hearing well in a conversational setting. Furthermore, occupations with a high Index have lower earnings, are more exposed to hazardous environments, and place less emphasis on high performance and problem-solving. Jobs with higher rates of workers who experience at least one difficulty with a job requirement have a higher share of workers receiving SSDI benefits within a 16-month period. Although the share of the population receiving SSDI increased from 1997 to 2010, the Index fell from 7.4 to 6.1 percent, suggesting that the increase could have been higher if not for the decline in health mismatch.
\end{abstract}




\section{Introduction}

Social Security Disability Insurance (SSDI) provides benefits to U.S. workers who cannot work due to health limitations. The criteria for evaluating whether applicants are medically eligible for SSDI involve not only examining their general health, but also their ability to hold down a job appropriate for their age, education, and work experience. These criteria indicate that most SSDI applicants must not only be in poor health, but in poor health that actually conflicts with the requirements of their occupation and other occupations. Yet most analyses aiming to explain the increase in the SSDI rolls between the mid-1980s and the early2010s have focused on factors related to general health, such as the aging workforce or mortality trends among beneficiaries (Liebman 2015) or factors related to the opportunity cost of applying, including the strength of the labor market (Maestas, Mullen, and Strand 2015), but not on the way in which workers' health interacts with their occupation's requirements.

As a result of this lack of focus, little is known about how SSDI activity relates to whether workers are able to perform the requirements of their specific occupation. The literature has found that being unable to perform requirements on the job due to physical limitations is associated with earlier retirement (Hudomiet et al. 2017, Sonnega et al. 2018), lower earnings (Kaye 2009; Jones and Sloan 2010; Jones et al. 2014; Choe and Baldwin 2017), and lower job satisfaction (Jones et al. 2014). However, no paper has looked at how health mismatch affects the likelihood of receiving SSDI benefits specifically or at the probability of leaving a job for health reasons, a potential precursor to SSDI use. This oversight seems notable given that the ability to do one's job is not only an explicit part of the SSDI evaluation process (Wixon and Strand 2013), but also likely weighs heavily in the minds of workers trying to decide whether to leave their jobs to apply for SSDI benefits.

This study aims to fill this gap in the literature by measuring the extent to which workers struggle to satisfy the health requirements of their jobs and to identify occupations where this health mismatch has been most common. It does so by devising a Health Mismatch Index, using the Survey of Income and Program Participation (SIPP) linked to the Occupational Requirement Survey (ORS), a new survey fielded by the U.S. Bureau of Labor Statistics in partnership with the U.S. Social Security Administration. The ORS collects information 
regarding physical demands, environmental exposure, education and training, and mental requirements from employers in nearly 20,000 different occupations. ${ }^{1}$ The SIPP includes a large, nationally representative sample of workers and their occupations, as well as detailed information on their health characteristics and DI receipt. Importantly, the health characteristics collected have a clear link to some of the occupational requirements listed for workers in the ORS. For example, the SIPP asks whether the respondent has any difficulty lifting a certain weight, pushing and pulling large objects, standing for long periods of time, or communicating effectively, all of which are physical requirements of the job asked about in the ORS. The paper defines its Health Mismatch Index as the share of workers in any given occupation who report at least one health limitation in the SIPP that the ORS marks as a requirement in the workers' current occupation. The paper also examines the sensitivity of the results where the Index is defined instead as the share of workers with at least two, or at least three, health limitations in their required abilities.

The results indicate that about 7 percent of workers report at least one health limitation in performing a requirement of their current occupation. The most frequent abilities with which workers report limitations are lifting 25 lbs., standing for one hour, and hearing clearly in a conversational setting. Some workers persevering through these limitations are employed in blue-collar jobs, but the occupations with the highest Index values are in health care, including nurses and health aides; education, including teacher assistants, early education teachers, and childcare workers; and personal services, including maids, housekeepers, and janitors. Interestingly, between 1997 and 2010, the Health Mismatch Index fell from 7.4 percent to 6.1 percent, despite the aging of the workforce. ${ }^{2}$

The study then examines whether occupations with the highest Index values see higher shares of workers receiving SSDI benefits. Over a 16-month period (the longest period in which workers can be followed consistently across SIPP panels after their health information is collected), occupations with higher values in the Health Mismatch Index had statistically

\footnotetext{
${ }^{1}$ The ORS is better designed to provide a closer association to SSA's evaluation process than the O*NET or the outdated Dictionary of Occupational Titles (DOT), which SSA uses currently despite lacking an update since 1991. The ORS has been used to examine the returns to different abilities (Gittleman, Monaco, and Nestoriak 2016), but to our knowledge no studies have used the ORS to examine actual or potential disability insurance activity.

${ }^{2}$ While more recent data is available - indicating that the Index was much higher in 2013, on the order of 11 percent - this information is derived from the 2014 panel of the SIPP, which has some important differences in survey techniques and the timing of when the health limitation questions were asked; therefore, these results are not comparable with earlier panels.
} 
significantly greater shares of their workers receiving SSDI benefits. The study also explores how the Index relates to the probability of workers leaving their jobs for health reasons, which does not correlate one-to-one with SSDI use, but may be a precursor for those not yet in the program when their time in the sample ends. If the Index is defined more conservatively as having at least $t w o$, rather than just one, health-related difficulties with job requirements, this alternative Index is also associated with a significantly greater share of workers who leave their jobs for health reasons during the following 16 months.

The strong relationship between the Health Mismatch Index and SSDI receipt rates suggests that, while SSDI receipt rates grew prodigiously during the Great Recession, an even greater share of workers may have ended up on SSDI during those years if not for the apparent fact that they were better able to satisfy the requirements of their jobs. Indeed, Maestas, Mullen, and Strand (2015) find that allowance rates fell during the Great Recession, perhaps because workers were less able to show that they could not hold a job in their most recent occupation.

The remainder of the paper is organized as follows. The second section describes the SIPP and ORS data. The third section outlines the methodology behind the Health Mismatch Index and the empirical models relating the Index to SSDI receipt and health-related job exit. The fourth section presents results, and the fifth section concludes that some occupations retain a relatively high share of workers who struggle with health limitations that may make it hard for them to maintain their jobs. Therefore, should employers and policymakers want to help workers at risk for a health mismatch, these occupations may be appropriate targets for interventions such as retraining for jobs that are more conducive to their health, or providing information to employees on how to apply to SSDI.

\section{Data}

\section{Survey of Income and Program Participation}

The analysis creates an occupation-level index of health mismatch using a broad sample of workers from the SIPP, a longitudinal dataset from the U.S. Census Bureau. The analysis uses the SIPP panels that began interviewing households in 1996, 2001, 2004, and 2008. ${ }^{3}$ Each of the

\footnotetext{
${ }^{3}$ The SIPP is in the process of releasing the 2014 panel. While it will provide more recent data on workers' health limitations, these data are not included in the main analysis because of concerns about comparability due to two substantive changes to the survey: 1) a longer recall window; and 2) nearly a one-year gap between the core SIPP questions and when health information was collected. Descriptive results about the Health Mismatch Index in 2013
} 
first four of these panels (1996-2008) interviewed households on the core questions once every four months, for a periods of three to five years. These core questions survey respondents on their labor market outcomes, sources of income, public program participation, demographics, family structure, and health insurance coverage. The longitudinal data from the SIPP core allows the analysis to follow workers across employers and occupations and potentially onto SSDI rolls.

These SIPP panels also included topical modules, which asked households about economic outcomes that vary less frequently. In the most relevant module for this analysis, adult respondents are asked about their general health status and whether they have difficulty with particular physical and communicative abilities. ${ }^{4}$ These questions are asked in the $5^{\text {th }}$ or $6^{\text {th }}$ interview waves of these four SIPP panels, which take place one to two years after the start of the panel; therefore, the analysis marks these observations as being from 1997, 2002, 2005, and $2010 .^{5}$

The sample is limited to individuals ages 18-64 who worked at some point in the four months leading up to their health interview and who had not received SSDI benefits up to that point. Respondents are asked about two jobs and two self-employment businesses per interview wave; their primary job is defined as the job or business in which they accumulated the most earnings during the wave of their health interview. The key variable for structuring the analysis is the occupation of their primary job. Other time-varying variables are also set at their value as of the wave of their health interview, or as of the calendar year of that wave in the case of earnings and total family income (and both are adjusted to 2014 dollars). ${ }^{6}$

The outcome variables take advantage of the SIPP core's longitudinal structure. Both variables focus on the 16 months following the health interview; this period is chosen because the minimum amount of time that workers remain in the SIPP after the health interview is four

are provided in the appendix, but show much higher Index values across the board indicating that the structural changes to the SIPP make the 2013 results not comparable to earlier panels.

${ }^{4}$ The topical module on health difficulties includes the standard battery of questions about Activities of Daily Living (ADLs). The ADL battery aims to establish whether a person can live independently; it asks whether the respondent has difficulty feeding oneself, bathing, dressing, getting out of bed, and using the toilet. The difficulties used in this analysis focus more on job requirements, though some variables overlap with the Instrumented Activities of Daily Living battery from disability research (e.g., telephone usage).

5 The 1996, 2001, and 2004 panel field the health topical module in Wave 5; the 2008 panel fields the module in Wave 6.

${ }^{6}$ Annual earnings and annual total family income are pro-rated to account for respondents who are not sampled in all 12 months of the health interview wave's calendar year. 
waves, or 16 months (the 2001 panel). ${ }^{7}$ The first outcome variable is the share of workers in an occupation who, over that 16-month period, start receiving SSDI benefits. ${ }^{8}$ The second outcome variable is the share of workers in an occupation who leave their jobs over that period for health reasons - that is, when asked their reason for leaving, they report their own illness or injury. Although this variable does not directly measure SSDI receipt, such an exit may be a precursor to SSDI receipt for those who are not observed in the program by the end of the 16-month sample.

\section{Occupational Data from the Occupational Requirement Survey}

The ORS supplies information on the physical demands, environmental conditions, mental and cognitive demands, and vocational preparation that are required in each job. The ORS interviews human resources specialists, occupational safety managers, or supervisors at selected companies about required abilities, knowledge, and environmental conditions for the jobs at that firm. The data used in this analysis come from the 2017 public-use survey. For each requirement, the ORS reports the share of workers in an occupation whose job requires that ability. These data are merged with SIPP data at the occupational level. Although the nature of jobs may change over time, the ORS data is currently only available for 2017 , so the same information on which abilities are required is used in each year.

\section{Methodology}

This study's goal is to calculate a Health Mismatch Index for each occupation using SIPP and ORS data, and then to examine how the Index correlates with SSDI receipt or health-related job separations. The Index represents the share of workers in any occupation, or across occupations, who report a health-related difficulty with a requirement for their occupation. The data on workers' reported difficulties comes from the SIPP; the information on whether an ability is required comes from the ORS.

\footnotetext{
7 The 1996 panel follows workers for 7 waves after the health interview wave; the 2004 panel for 7 waves; and the 2008 panel for 10 waves.

${ }^{8}$ The SIPP does not include much information about SSDI application; it asks respondents only once whether they have applied to SSDI in the prior 12 months. This question is asked as part of the health interview, and only one panel (2008) has a second health interview wave. So for most respondents, it would not be possible to examine whether they apply to SSDI after their health mismatch is evaluated.
} 
The analysis begins by collapsing the SIPP data to the occupation level (or occupationyear level), using each worker's primary occupation in the health interview wave. The occupation-level sample uses the 178 unique occupations that are identified in both the SIPP and ORS and that have at least 20 workers in at least one panel; occupations with fewer workers are combined with similar occupations. ${ }^{9}$ The analysis then creates an index associating health difficulties reported in the SIPP with job requirements from the ORS. The SIPP health questions do not ask about whether health affects work per se, just whether the individual has trouble doing those job requirements in any context; for example, respondents may have trouble climbing stairs or lifting $25 \mathrm{lbs}$., which could occur in work or in everyday life. As a result, the analysis merges information from the ORS that is specific to work-related requirements.

The analysis selects health-related requirements from the ORS that correspond most closely with the health difficulty variables from the SIPP. Those ORS variables are (with further detail from the corresponding SIPP variable in parentheses):

- Reaching overhead;

- Pulling or pushing with hands or arms;

- Fine manipulation (SIPP: using one's fingers to grasp, e.g., a glass or a pencil);

- Climbing ramps or stairs (SIPP: a flight of 10 stairs);

- $\quad$ Stooping (SIPP: stooping, crouching, or kneeling) ${ }^{10}$;

- Near visual acuity (SIPP: seeing, even with glasses or contacts);

- Communicating verbally (SIPP: having speech understood in primary language);

- Hearing in one-on-one conversation (SIPP: hearing, even with a hearing aid);

- Hearing on the telephone (SIPP: using an ordinary telephone) $;^{11}$

- $\quad$ Sitting for one hour or more;

\footnotetext{
${ }^{9}$ Nearly all occupations had at least 30 workers in each panel (or could be combined with similar occupations to reach this level), except for a few occupations that did not fit naturally with other occupations, such as veterinarians, wastewater treatment plant workers, and refuse and recyclable material collectors. In the analysis with subgroups defined by age, any occupation-year observations with fewer than 20 workers in that age group were excluded. ${ }^{10}$ The ORS includes separate variables for requiring stooping, crouching or kneeling, but the SIPP groups these variables together. Unfortunately, without more information on the overlap between these variables (e.g., the share of workers who required stooping but not kneeling vs. stooping and kneeling), ORS variables cannot be added together, averaged, or otherwise combined. The analysis, therefore, uses the stooping variable from the ORS because more jobs required stooping than either crouching or kneeling.

${ }^{11}$ Because "using the telephone" might also refer to finger dexterity or comfort with technology, the analysis has also examined results excluding this variable from the health mismatch index. This difficulty is the least-common one among SIPP respondents, so not surprisingly the results are almost identical with telephone usage excluded.
} 
- Standing for one hour or more;

- Lifting 10 lbs. (SIPP: e.g., a bag of groceries); and

- Lifting 25 lbs. (SIPP: e.g., a large bag of pet food)

The ORS variables' values represent the share of workers at the sampled employers for whom the above abilities are required. For example, among all occupations, the median share of workers required to reach overhead is 60 percent. For most ORS variables, this study marks an occupation as requiring a specified ability if the occupation's share of workers with that requirement is above that requirement's median across all occupations. In the above example, this study defines any occupation as requiring workers to reach overhead if its ORS share was at least 60 percent. ${ }^{12}$ The analysis then calculates the share of workers having difficulty in that ability in the occupations in which it is required.

The paper presents results from three versions of the Health Mismatch Index. The main analysis defines the Index as the share of workers in an occupation that have one or more difficulties with job requirements. However, having a single difficulty need not predict exit from the workforce if employers are able to make accommodations for that difficulty; therefore, the analysis also presents results using the Index calculated as the share of workers with two or more, or three or more, difficulties with job requirements. The first calculations performed with these indices are descriptive: the average Health Mismatch Index over time and by age; its correlation with the median earnings in each occupation; the most common difficulties in job requirements; and the occupations with the 15 highest mismatch index values.

The paper also estimates the relationship between the Health Mismatch Index and two outcome variables: the share of workers in the occupation receiving SSDI benefits within the 16month window and the share in the occupation leaving their jobs for health reasons. Because these variables are percentages, the regressions are specified as Tobits with $[0,1]$ bounds. Linear

\footnotetext{
${ }^{12}$ For a few abilities, the requirement was nearly universal. For example, almost all occupations reported that 100 percent of its workers had to use near visual acuity, so the ability to see (with corrective lenses) is marked as a requirement for all jobs. Hearing in one-on-one conversation and having speech understood are also marked as being required in all occupations. Therefore, any worker who reports difficulty seeing, hearing, or having their speech understood is marked as having a difficulty with that required ability. Finally, other abilities are highly concentrated at high or low values; in these cases, a threshold was chosen to ensure variation across occupations. For example, most jobs have low shares reporting that workers have to be able to climb a set of stairs, but some occupations do require climbing stairs, so the analysis sets a threshold at 50 percent.
} 
results are similar (and available upon request), but the dependent variables have low means, so the Tobit specification ensures that predicted values remain within the $[0,1]$ bounds.

The following regression model is estimated on occupation-year-level data:

$$
Y_{j t}=f\left[\beta_{0}+\beta_{1} \text { Mismatch }_{j t}+X_{j t}^{\prime} \gamma+\tau_{t}\right]+\varepsilon_{j t}
$$

where Mismatch $_{j}$ represents the Health Mismatch Index for occupation $j$ in year $t, \tau_{t}$ represents year fixed effects, and $f$ represents the Tobit model's functional form. The coefficient of interest is $\beta_{1}$; a positive coefficient indicates that a greater share of workers leave a job for health reasons or enter the SSDI rolls in occupations where a higher share have difficulty with required abilities. Though the coefficient should not be interpreted as a causal effect due to worker self-selection into occupations throughout their careers, a positive coefficient suggests that occupations with high Health Mismatch Index scores may be a source of future SSDI beneficiaries.

The regression also controls for a vector of occupation-level characteristics, $X_{j t}^{\prime}$ that may also impact workers' ability to do the job when unhealthy. This vector includes the number of job requirements, as an occupation with more requirements may be more complex or require more versatility. $X_{j t}^{\prime}$ also includes characteristics capturing working conditions, based on information from the O*NET, a predecessor of ORS. ${ }^{13}$ The O*NET data are used to create three indices of working conditions that could exaggerate or mitigate the effect of health: 1) workers' exposure to hazardous work environments; 2) the job's emphasis on performance and problemsolving; and 3) workers' need for teamwork and emotional balance. ${ }^{14}$ The analysis also controls

\footnotetext{
${ }^{13}$ The O*NET surveys workers and occupational experts to create a picture of an occupation's typical employee and typical work environment. While the ORS focuses more on the concrete and quantifiable aspects of an employee's job - the tangible environmental hazards, required physical abilities, cognitive demands, education and experience the O*NET also looks at the overall context in which the work is performed. For instance, it looks at various work styles and values that are necessary for job performance, as well as the emphasis placed on cooperation, competition, and different types of communication. The analysis incorporates $\mathrm{O}$ *NET information to better account for occupational differences in the tangible and intangible context in which work is performed.

14 These indices are created using factor analysis; the components of these indices are available upon request. Cronbach's $\alpha$ is 0.8964 for the dangerous environment index, 0.8948 for the high performance and problem-solving index, and 0.9147 for the teamwork and emotional balance index, which suggest that each of the constructed indices is highly correlated with its associated latent variable. Since Cronbach's $\alpha$ is lower when jointly tested on all of the indices' components (0.8162), it suggests that the underlying work environment variables are in fact distinct from each other and cannot be captured through the use of only one variable.
} 
for a variable accounting for whether a job is highly automated, based on information available in $\mathrm{O}^{*} \mathrm{NET}$, as automated jobs may be easier for workers with health problems. ${ }^{15}$ $X_{j t}^{\prime}$ additionally includes the demographic composition of occupation $j$ 's workforce: the share under 50, female, married, by race and Hispanic ethnicity, and by education. The vector also includes the median family income of workers in that occupations excluding their own earnings, which represents their family income should they leave their job and may affect their decisions about labor supply and SSDI activity. Finally, $X_{j t}^{\prime}$ includes job characteristics such as median earnings, the share with employer-sponsored health benefits, and the share of the workforce in firms with fewer than 100 employees, all of which may be associated with the share of workers leaving a job for health reasons or exiting into the SSDI program.

\section{Results}

Descriptive Results

The first part of this section focuses on changes in the Index over time, before focusing on how it varies across occupations.

The Health Mismatch Index Over Time. Most workers have no problem carrying out the day-to-day requirements of their job, but a sizeable contingent are managing to work despite health-related difficulties with job requirements. As indicated by Figure 1, 7.4 percent of workers in 1997 experienced difficulty with at least one job requirement - that declined to about 6 percent in 2010. This decrease seems largely driven by the share experiencing difficulty with exactly one job requirement, which fell from 4.5 percent in 1997 to 3.6 percent in 2010 . In contrast, between 1997 and 2010, the shares of the workforce that had difficulty with exactly two job requirements and 3 or more job requirements stayed relatively constant. Not surprisingly, while all workers report work-health mismatches, those who are at least 50 years old do so at a more frequent rate than those who are younger than 50 (see Figure 2); consistently across interview waves, about 70 percent of those experiencing at least one health-job mismatch are age

\footnotetext{
15 The O*NET asks respondents "How automated is your current job?", with responses options of "Not at all automated", "Slightly automated", "Moderately automated", "Highly automated", and "Completely automated." The analysis aggregates the share reporting high or complete automation to the occupational level and then uses this share as a regression control.
} 
50 or older. However, both younger and older workers had lower levels of health mismatch in 2010 than in 1997.

Figure 3 summarizes the exact nature of the job requirements people are unable to fulfill; the most common are lifting 25 pounds and standing for one hour. Interestingly, some of the top 15 occupations that had the highest Health Mismatch Index values from 1997 through 2010 are in health care and education, perhaps in part because those jobs require lifting or standing (see Table 1a for the Index defined as having one or more difficulties, and Table $1 \mathrm{~b}$ for two or more difficulties; results are similar between these two definitions of the Index). Another set of jobs with high Index values includes low-skilled service-sector work, primarily in food service and custodial, that also involves lifting and standing.

Characteristics of Jobs with High Health Mismatch Index Values. As suggested by some of the occupations with the highest Index values, lower-paying occupations have higher shares of health-job mismatch (Figure 4). ${ }^{16}$ Occupations with more hazardous work environments also have higher mismatch (Figure 5). ${ }^{17}$ In other words, jobs with high mismatch are also associated with other characteristics that could lead to early exit, motivating their inclusion as controls in the regression analysis.

Another interesting question is what kinds of jobs enable workers to remain working even though they have a health mismatch. One possibility is that these workers are in jobs where performance is not evaluated frequently, allowing workers with health limitations to fly under the radar. As expected, Figure 6 shows that jobs emphasizing high performance tend to have a lower mismatch rate, since people in these jobs are likely to be forced to exit once their productivity declines. Another possibility is that these workers are in environments that are

\footnotetext{
${ }^{16}$ The negative correlation between earnings and the Health Mismatch Index is consistent with studies that find that skills mismatch is associated with lower wages and fewer hours worked (Kaye 2007; Jones et al. 2014; Choe and Baldwin 2017. In addition, Jones et al. (2014) find that mismatch is associated with lower productivity, which may result in lower wages. And lower-paid occupations are also less likely to offer generous health benefits, which may indirectly contribute to a higher health mismatch rate - employees may have difficulty accessing preventative care or addressing new health issues in a timely way.

17 This result is in line with Michaud and Wiczer (2014), who find that those who work in risky occupations end up with higher rates of health limitations. Results are qualitatively similar with quartiles and quintiles, with a slight decline of the Health Mismatch Index from the second-highest to the highest categories of these specifications. A simple linear regression shows a statistically significant positive relationship between the Index and hazardous work environments, while a quadratic regression indicates that the Index increases at a decreasing rate for increasingly hazardous work environments.
} 
more supportive and their employers make accommodations for their employees. On this front, Figure 7 shows that the relationship is less monotonic. Jobs with high levels of teamwork and emotional balance do have high levels of mismatch, showing that these jobs may support workers and help them adjust when health problems arise that interfere with typical job requirements. However, at low levels of teamwork and emotional balance, the Index is also high, perhaps because coworker and supervisors are less aware of health problems.

The Health Mismatch Index and Labor Market Outcomes. Having health-related difficulty meeting job requirements would certainly be felt by the individual, but would this be enough to prompt the utilization of SSDI or at least a job exit? The extent to which occupations have high rates of health mismatch does appear to predict these outcomes. Figures 8 and 9 split the occupations into four categories: terciles defined by the share of workers in each occupation receiving SSDI or leaving for health reasons, and a separate group of occupations that had no workers observed with these outcomes in the SIPP. As expected, the occupations in which a higher share become SSDI beneficiaries or leave for health reasons have a higher Health Mismatch Index (for each level of Index severity).

The analysis next examines whether these relationships hold up when controlling for other job attributes and the demographics of an occupation's workforce. Employers may be able to arrange accommodations for workers experiencing difficulty with only one job requirement, but difficulty with multiple requirements may be too acute for both the employee and employer to ignore. To test this, the analysis estimates the impact of differing levels of mismatch severity in separate Tobit regressions where the Health Mismatch Index is defined as the share of an occupation's workforce that has health-related difficulty with 1 or more, 2 or more, or 3 or more job requirements.

The first column in Table 3 shows the estimated relationship between the Health Mismatch Index and an occupation's share of health-related job departures and SSDI beneficiaries. The regressions show a positive, statistically significant relationship with the Index, even at the lowest level of mismatch severity (i.e., 1 or more difficulties). The Tobit results imply that a 10-percentage-point increase in the share of an occupation with one or more difficulties would be associated with a 0.45 -percentage-point increase in the share of that occupation's workers who receive SSDI within the next 16 months. This increase would nearly 
double the share of workers who end up in SSDI (a sample mean of 0.49; see Table 2). The estimated relationship between health mismatch and an occupation's share of future SSDI beneficiaries is stronger for an older workforce than a younger one. The finding that older workers are more responsive to mismatch may be an artifact of their longer work experience they are more likely than younger peers to accumulate enough working years to meet the minimum required for SSDI application, should the need arise.

The second column of Table 3 shows the results for health-related job exit. The results indicate that there is a small, positive relationship between an occupation's Health Mismatch Index and the share of workers leaving their job for health reasons in the next 16 months. While the relationship is not statistically significant when the Index is defined as one or more difficulties, it becomes larger and statistically significant as the Index increases to 2 or more or difficulties, especially, 3 or more. This result suggests that employers might be able to arrange accommodations for workers experiencing difficulty with one requirement or that workers are better able to work around their problem with one requirement - but not when workers are unable to satisfy multiple requirements. This increase is slightly more pronounced for workers ages 18-49 than for those ages 50-64. The different responses in the measures of health mismatch might be a reflection of younger workers' greater openness to career changes, or perhaps an older worker's aim to ride out their job until retirement benefits become available. It could also be evidence of survivor bias - that is, older workers may be better able to negotiate accommodations with their employers that allow them to avoid leaving for health reasons.

Other regression coefficients are largely in line with expectations. In the SSDI receipt regressions, the number of job requirements, the share of workers under 50, the share covered by employer insurance, the share at smaller employers, and the emphasis placed on worker performance and problem solving exhibit a negative relationship, while the degree of teamwork and emotional balance required of workers is positively related to the share of an occupation's employees who become SSDI beneficiaries. In the health-related exit regressions, an occupation's share of female workers, and the degree of teamwork and emotional balance are positively related to the share of health-related job departures. The share of workers younger than 50 in an occupation, the share covered by employer health insurance, median family income (excluding own earnings), the degree to which automation is used in that job, and the occupational emphasis on performance and problem-solving are all negatively related to the 
share of workers within an occupation who leave due to health-related reasons. The magnitudes of these relationships, as well as the full regression results, are in appendix Tables A1 and A2.

\section{Conclusion}

This study explores the mismatch between job requirements and workers' health. To that end, the analysis calculates a Health Mismatch Index using ORS and SIPP data to examine the prevalence of workers having health-related difficulties with their job requirements, the occupational characteristics associated with a high value for that Index, and whether a high Index value is associated with health-related job departures and SSDI activity.

The results show that the percentage of the U.S. workforce experiencing difficulty with at least one job requirement - usually physically taxing activities such as lifting heavy objects and standing for one hour or activities that depend on more easily damaged sensory organs such as hearing and sight - slightly declined between 1997 and 2010. Occupations with a high Health Mismatch Index tend to have lower median earnings and more hazardous work environments and place a lower emphasis on high performance. The Index is also associated with a higher share of the occupation's workforce receiving SSDI or leaving for health reasons. While the reasons behind the Index's decline remain to be uncovered, it may be that workers have recently gotten better at sorting themselves into jobs that fit their abilities or that work environments have become less dangerous and physically exacting over time.

Given the positive relationship between the Health Mismatch Index and health-related labor market outcomes, both the Index and its correlates should be of interest to policymakers such as the Social Security Administration and the Occupational Safety and Health Administration. By proactively investigating or targeting health and safety interventions and helping to arrange worker accommodations in highly mismatched occupations, workers' wellbeing could be improved while potentially removing the impetus for health-related attrition and SSDI activity. Policymakers could also reach out to populations at risk of entering SSDI, either by offering information on the application process or targeting job-retraining programs. The results of this analysis indicate that highly mismatched occupations would be efficient starting points. 


\section{References}

Choe, Chung and Marjorie L. Baldwin. 2017. "Duration of Disability, Job Mismatch and Employment Outcomes." Applied Economics 40(10): 1001-1015

Gittleman, Maury, Kristen Monaco, and Nicole Nestoriak. 2016. "The Requirements of Jobs: Evidence from a Nationally Representative Survey.” Working Paper. Washington, DC: U.S. Bureau of Labor Statistics.

Hudomiet, Peter, Michael D. Hurd, Susann Rohwedder, and Robert J. Willis. 2017. "The Effect of Physical and Cognitive Decline at Older Ages on Work and Retirement: Evidence from Occupational Job Demands and Job Mismatch.” Working Paper R-UM17-10. Ann Arbor, MI: University of Michigan Retirement Research Center.

Jones, Melanie and Peter J. Sloane. 2010. "Disability and Skill Mismatch" The Economic Record 86:101-114.

Jones, Melanie, Kostas Mavromaras, Peter Sloane, and Wei Zhang. 2014. "Disability, job mismatch, earnings and job satisfaction in Australia" Cambridge Journal of Economics 38: $1221-1246$.

Kaye, H. Stephen. 2009. "Stuck at the Bottom Rung: Occupational Characteristics of Workers with Disabilities.” Journal of Occupational Rehabilitation 19: 115-128.

Liebman, Jeffrey B. 2015. "Understanding the Increase in Disability Insurance Benefit Receipt in the United States." Journal of Economic Perspectives 29(2): 123-150.

Maestas, Nicole, Kathleen J. Mullen, and Alexander Strand. 2015. "Disability Insurance and the Great Recession.” American Economic Review 105(5): 177-182.

Michaud, Amanda M. and David G. Wiczer. 2014. "Understanding the Motives and Constraints That Lead People to Risky Occupations." The Regional Economist 1-2014. Federal Reserve Bank of St. Louis.

Sonnega, Amanda, Brooke Helppie-McFall, Peter Hudomiet, Robert J. Willis, and Gwenith G. Fisher. 2018. "A Comparison of Subjective and Objective Job Demands and Fit with Personal Resources as Predictors of Retirement Timing in a National U.S. Sample" Work, Aging and Retirement (1): 37-51.

Wixon, Bernard and Alexander Strand. 2013. "Identifying SSA's Sequential Disability Determination Steps Using Administrative Data." Research and Statistics Note 2013-01. Washington, DC: Social Security Administration Office of Research, Evaluation, and Statistics. 
Figure 1. Share of U.S. Workers Experiencing Difficulty with Health-Related Job Requirements, by Year

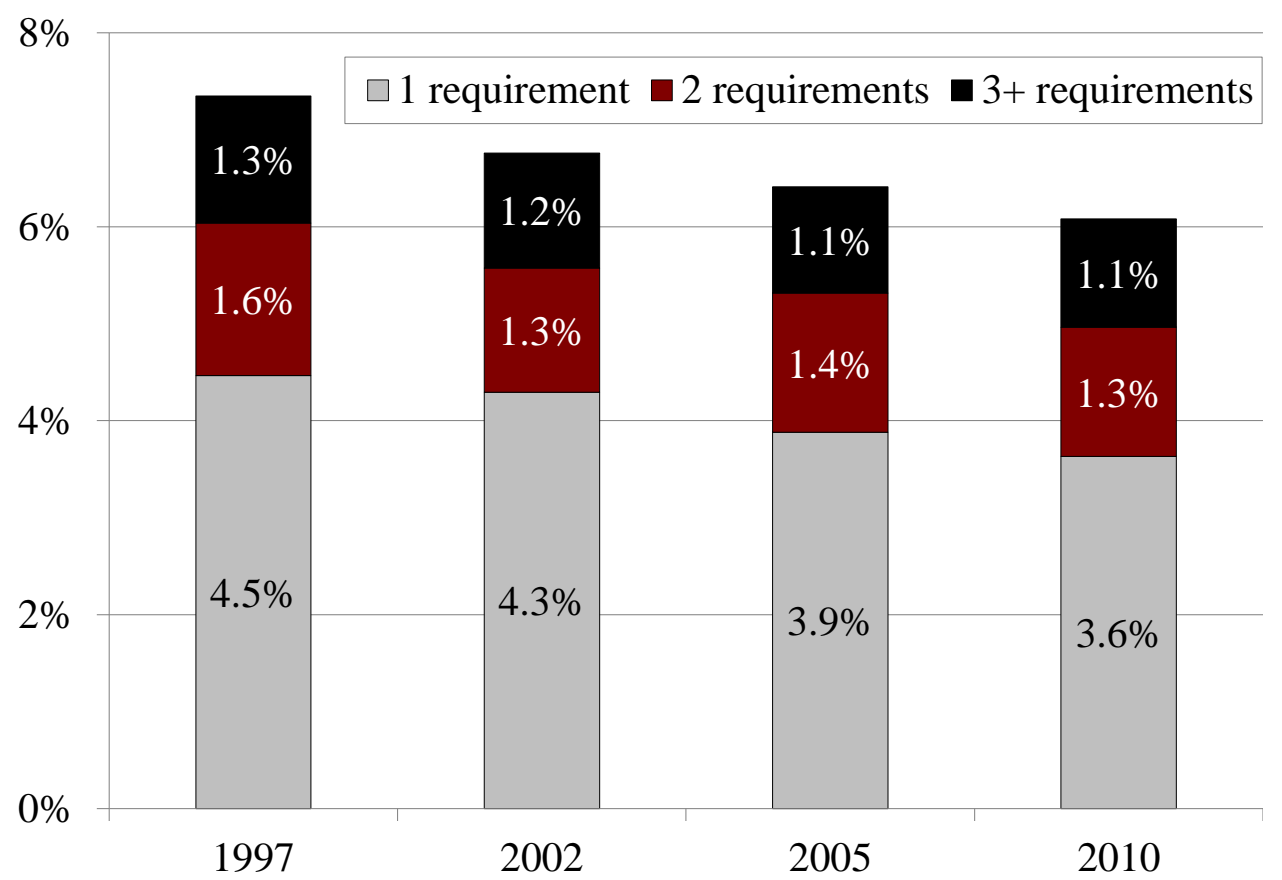

Sources: Authors' calculations from the Survey of Income and Program Participation (SIPP), 1996-2008 panels; and the Occupational Requirement Survey (ORS), 2017.

Figure 2. Share of U.S. Workers Experiencing Difficulty with Health-Related Job Requirements, by Age and Year

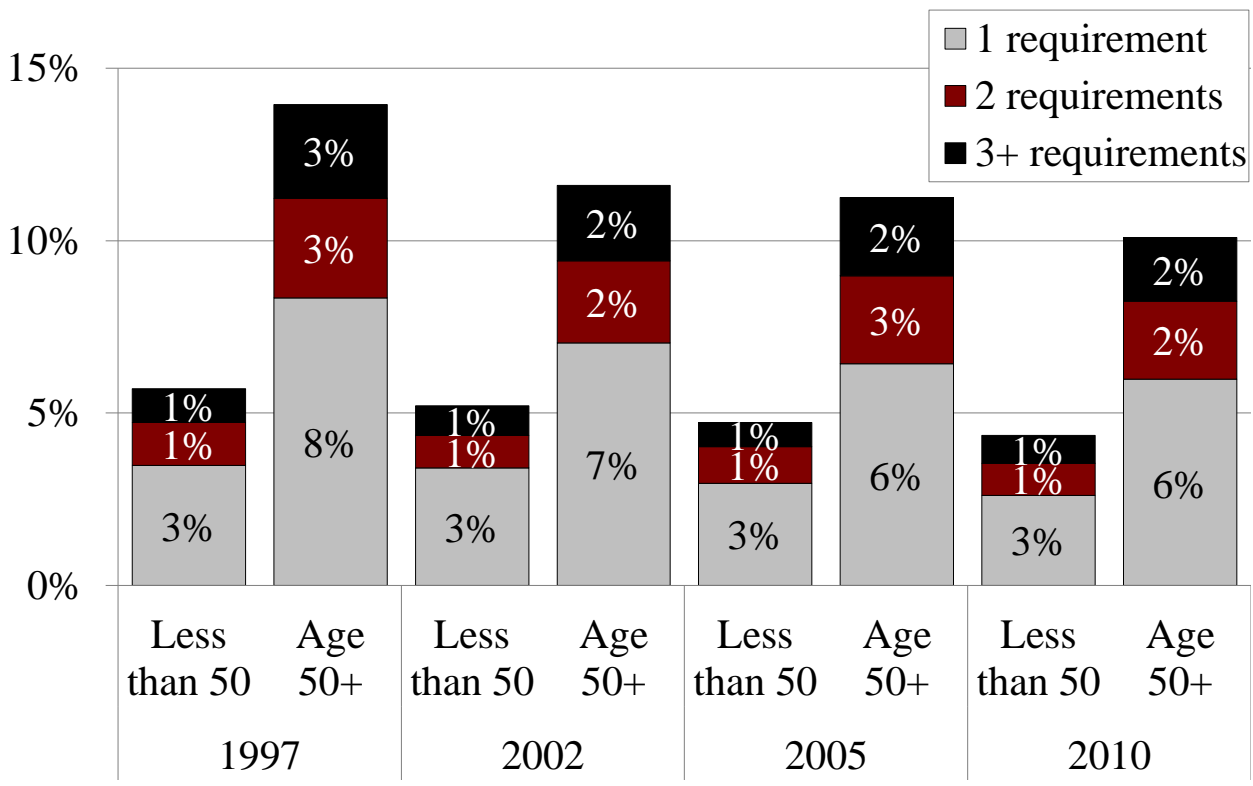

Note: Age categories include 18-49, and 50-64.

Sources: Authors' calculations from the SIPP, 1996-2008 panels; and the ORS, 2017. 
Figure 3. Share of U.S. Workers Experiencing Each Specific Difficulty When It's a Job Requirement

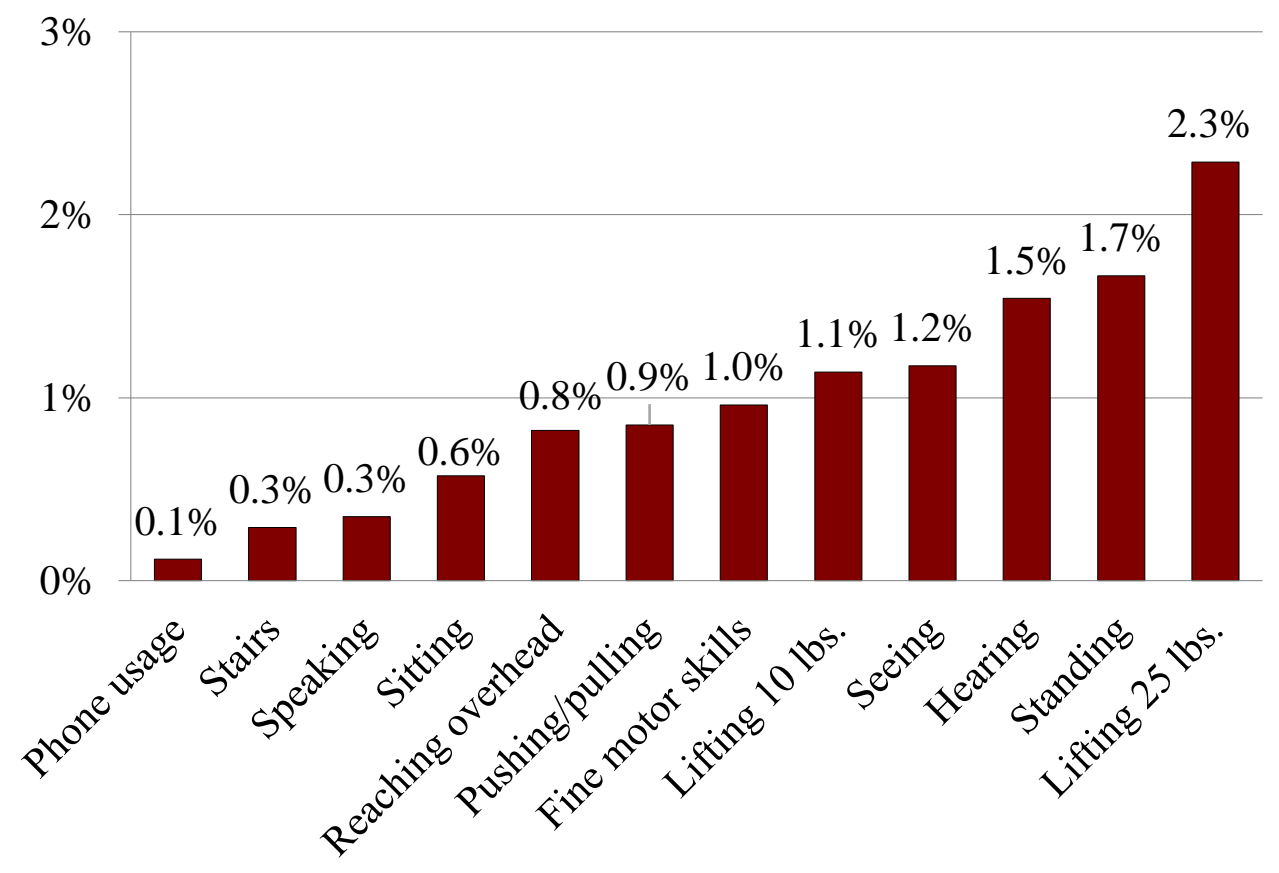

Sources: Authors' calculations from the SIPP, 1996-2008 panels; and the ORS, 2017.

Figure 4. Share of U.S. Workers Experiencing Difficulty with Health-Related Job Requirements, by Earnings Quartile

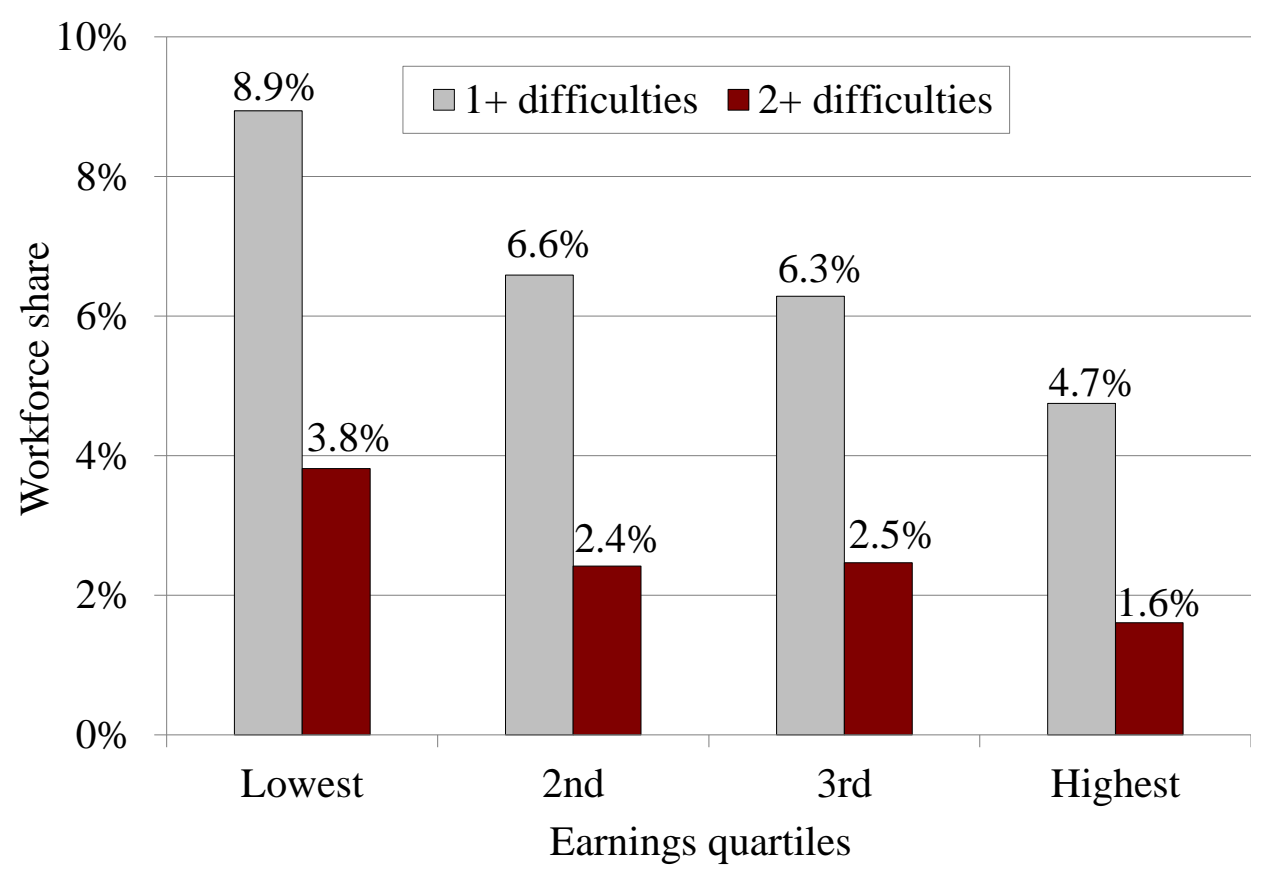

Sources: Authors' calculations from the SIPP, 1996-2008 panels; and the ORS, 2017. 
Figure 5. Share of U.S. Workers Experiencing Difficulty with Health-Related Job Requirements, by Tercile of Hazardous Work Condition Index

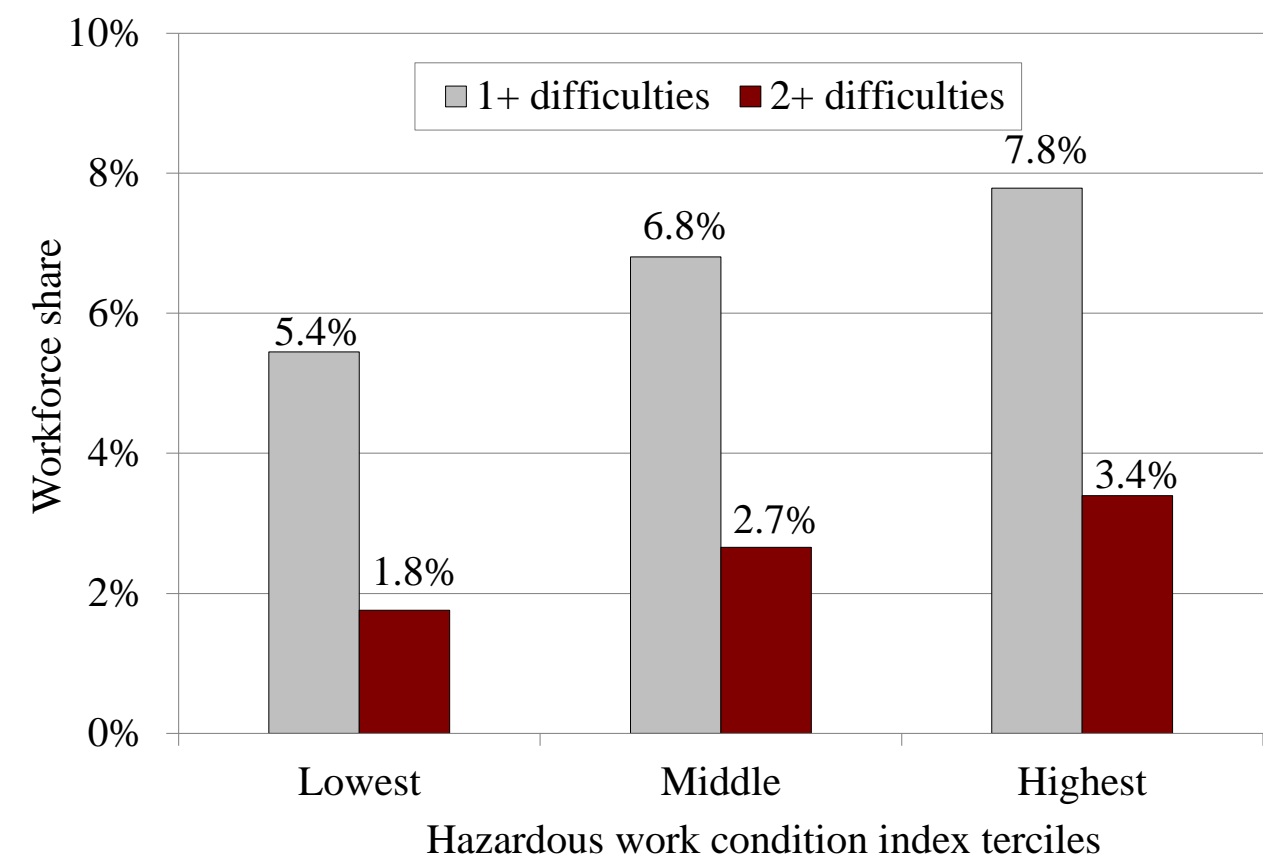

Sources: Authors' calculations from the SIPP, 1996-2008 panels; ORS, 2017; and the May O*Net Release, 2018.

Figure 6. Share of U.S. Workers Experiencing Difficulty with Health-Related Job Requirements, by Quartile of High Performance and Problem-Solving Index

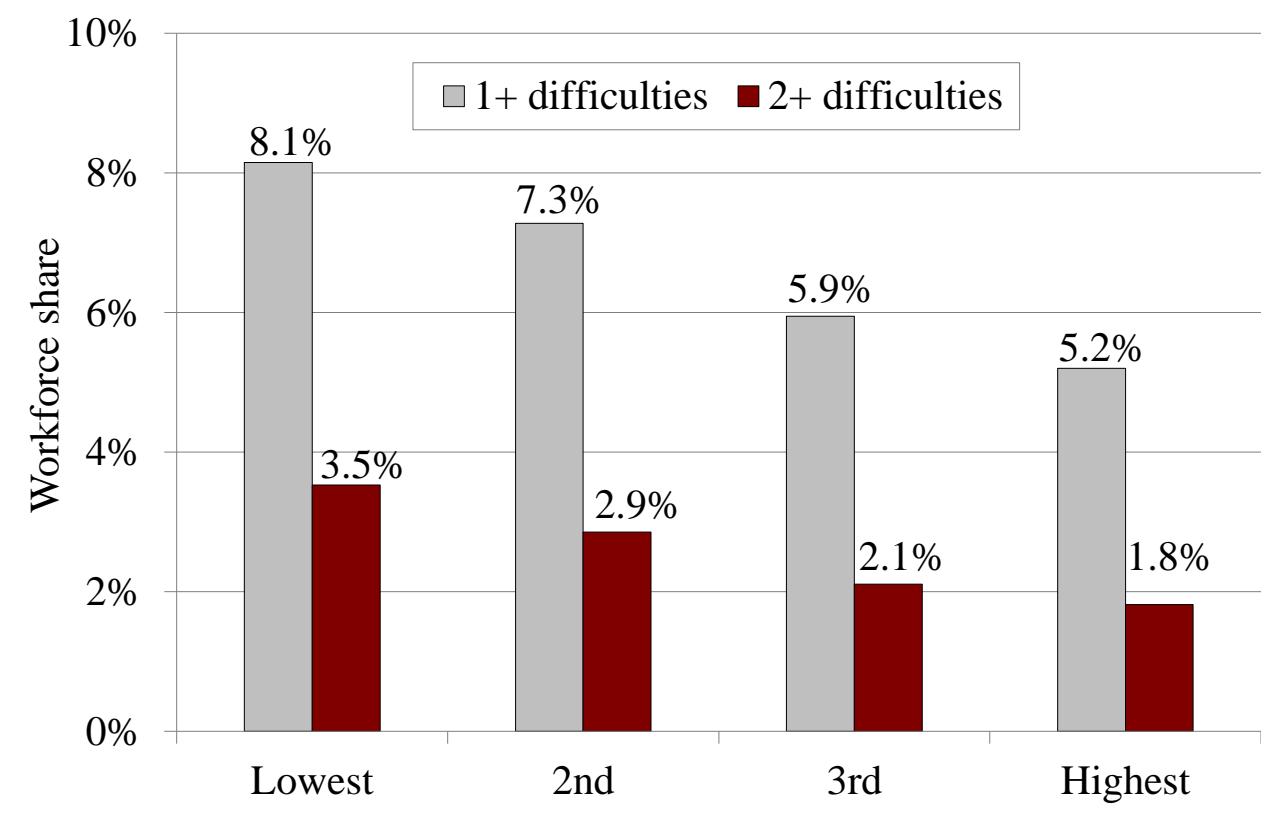

High performance and problem-solving index quartiles

Sources: Authors' calculations from the SIPP, 1996-2008 panels; ORS, 2017; and the May O*Net Release, 2018. 
Figure 7. Share of U.S. Workers Experiencing Difficulty with Health-Related Job Requirements, by Quintile of Social Skills Index

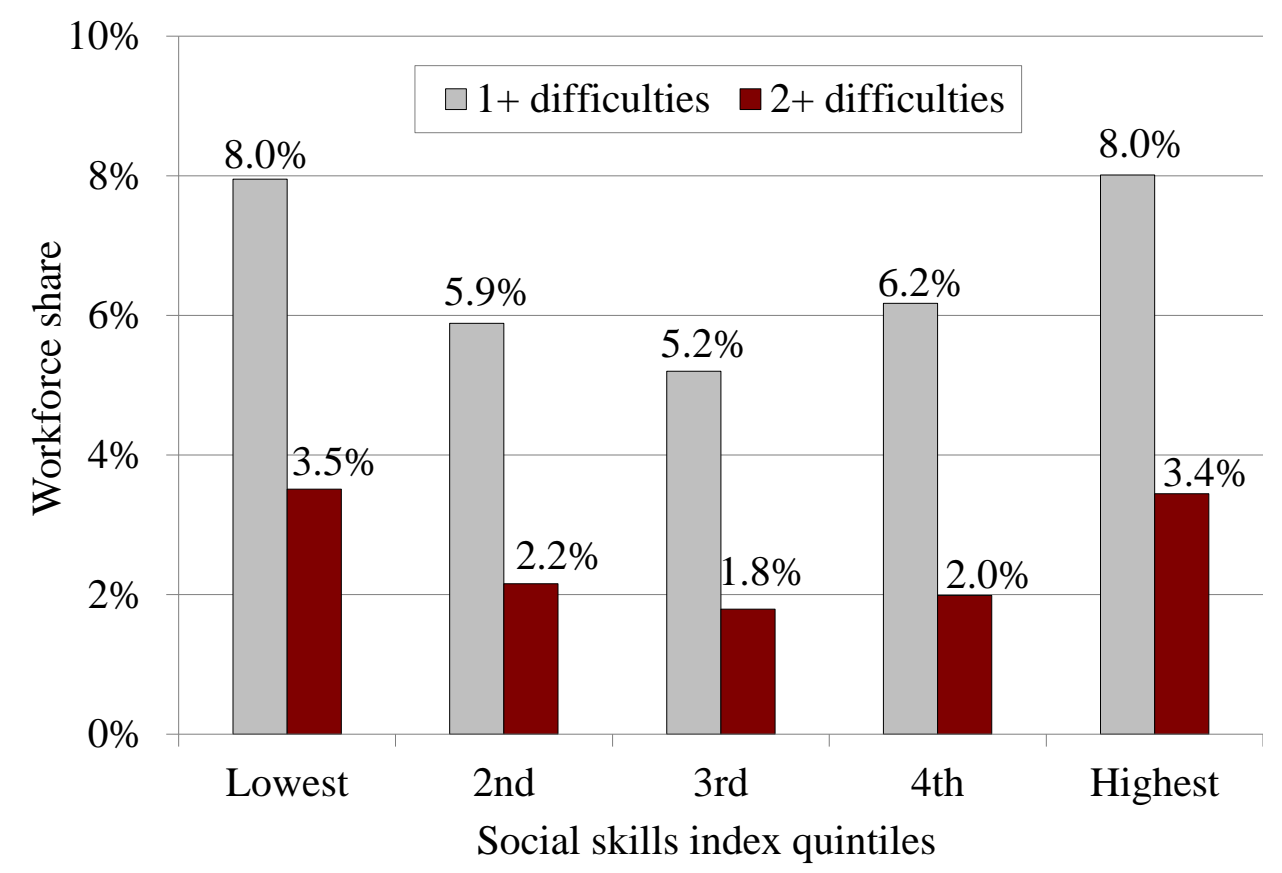

Sources: Authors' calculations from the SIPP, 1996-2008 panels; ORS, 2017; and the May O*Net Release, 2018. 
Figure 8. Share of U.S. Workers Experiencing Difficulty with Health-Related Job Requirements, by Share of Occupation Receiving SSDI in the Next 16 Months

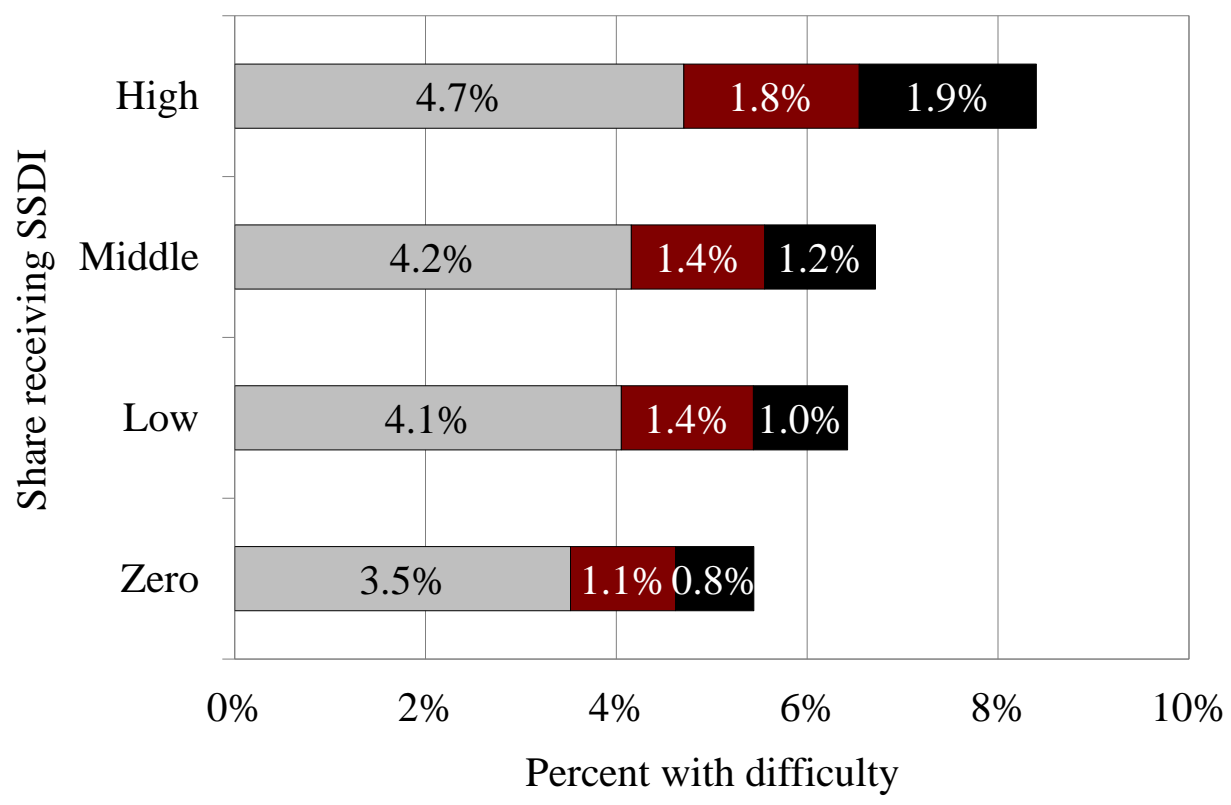

\section{1 requirement $\square 2$ requirements $\boldsymbol{\square} 3+$ requirements}

Sources: Authors' calculations from the SIPP, 1996-2008 panels; and the ORS, 2017.

Figure 9. Share of U.S. Workers Experiencing Difficulty with Health-Related Job Requirements, by Share of Occupation Leaving for Health Reasons in the Next 16 Months

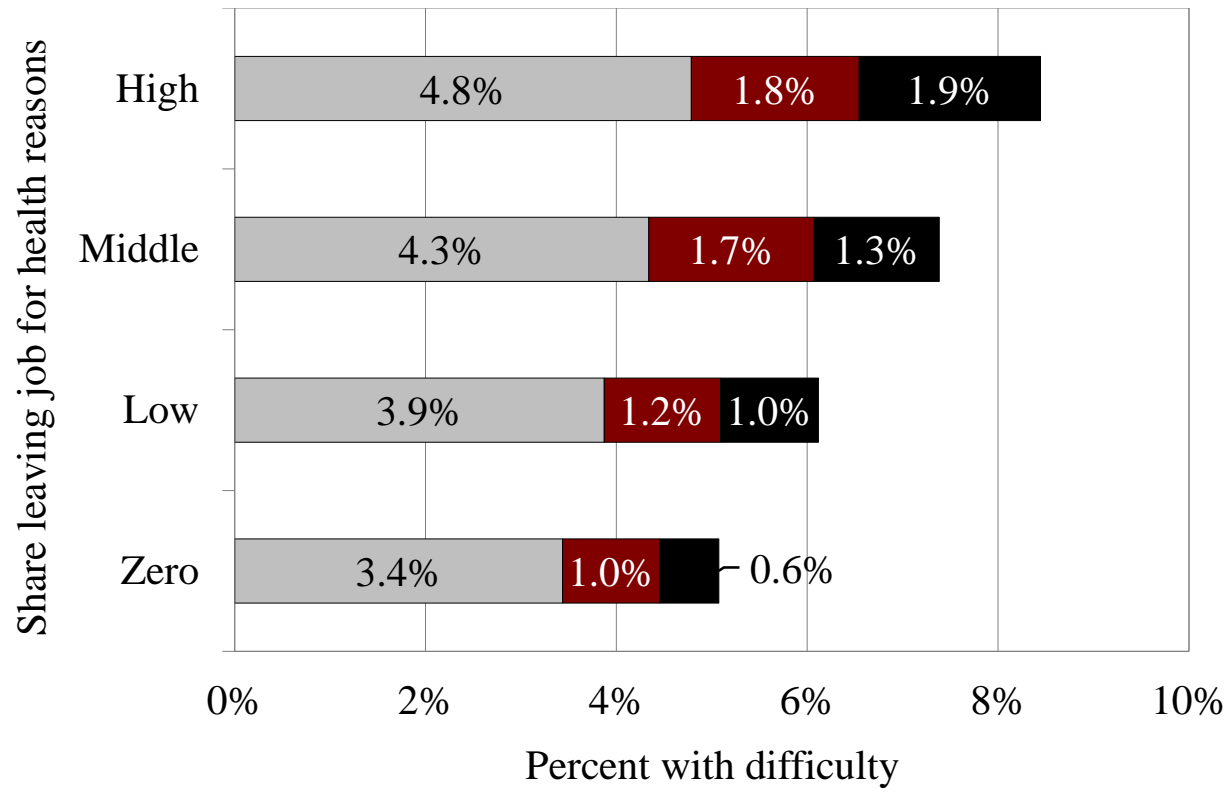

1 requirement $\square 2$ requirements $\square 3$ + requirements

Sources: Authors' calculations from the SIPP, 1996-2008 panels; and the ORS, 2017. 
Table 1a. Top 15 Occupations with the Highest Share of Workers with 1+ Difficulty with HealthRelated Job Requirements, 1997-2010

\begin{tabular}{llc}
\hline Rank & Occupation & $\begin{array}{c}\text { Share with } \\
1+\text { difficulty }\end{array}$ \\
\hline 1 & Hosts, hostesses, and counter attendants, restaurants and cafeterias & $14.8 \%$ \\
2 & Licensed practical and licensed vocational nurses & 14.6 \\
3 & Teacher assistants & 13.8 \\
4 & Personal care aides & 13.8 \\
5 & First-line supervisors of housekeeping and janitorial workers & 12.8 \\
6 & Bus drivers & 12.1 \\
7 & Maids and housekeeping cleaners & 11.6 \\
8 & Dining room and cafeteria attendants and bartender helpers & 11.1 \\
9 & Printing press operators & 11.0 \\
10 & Nursing, psychiatric, and home health aides & 10.8 \\
11 & Clinical laboratory technologists and technicians & 10.6 \\
12 & Preschool and kindergarten teachers & 10.6 \\
13 & Cooks & 10.5 \\
14 & Childcare workers & 10.4 \\
15 & Cashiers & 10.3 \\
\hline
\end{tabular}

Table 1b. Top 15 Occupations with the Highest Share of Workers with 2+ Difficulty with HealthRelated Job Requirements, 1997-2010

\begin{tabular}{llc}
\hline Rank & Occupation & $\begin{array}{c}\text { Share with } \\
2+\text { difficulties }\end{array}$ \\
\hline 1 & Licensed practical and licensed vocational nurses & $7.8 \%$ \\
2 & Teacher assistants & 7.8 \\
3 & Maids and housekeeping cleaners & 6.4 \\
4 & Bus drivers & 5.8 \\
5 & Security guards & 5.6 \\
6 & Printing press operators & 5.5 \\
7 & Nonfarm animal caretakers & 5.5 \\
8 & Janitors and building cleaners & 5.5 \\
9 & First-line supervisors of personal service workers & 5.1 \\
10 & Installation, maintenance, and repair workers, all other & 5.1 \\
11 & Cooks & 5.0 \\
12 & Personal care aides & 5.0 \\
13 & Nurses and physician assistants & 4.8 \\
14 & Welding, soldering, and brazing workers & 4.7 \\
15 & Childcare workers & 4.7 \\
\hline
\end{tabular}

Sources: Authors' calculations from the SIPP, 1996-2008 panels; and the ORS, 2017. 


\begin{tabular}{|c|c|c|c|}
\hline & \multirow{2}{*}{ All workers } & \multicolumn{2}{|c|}{ By age } \\
\hline & & $18-49$ & $50-64$ \\
\hline Health Mismatch Index (1+ difficulties) & $6.65 \%$ & $5.04 \%$ & $11.49 \%$ \\
\hline Health Mismatch Index (2+ difficulties) & 2.58 & 1.91 & 4.69 \\
\hline Health Mismatch Index (3+ difficulties) & 1.18 & 0.87 & 2.21 \\
\hline Leaving for health reasons in 16 months after health interview & 0.71 & 0.61 & 0.99 \\
\hline DI receipt in next 16 months after health interview & 0.49 & 0.31 & 1.03 \\
\hline O*NET hazardous work environments index & -0.14 & -0.14 & -0.21 \\
\hline $\mathrm{O} *$ NET high performance and problem-solving index & -0.21 & -0.23 & -0.11 \\
\hline $\mathrm{O} *$ NET social skills index & 0.23 & 0.23 & 0.29 \\
\hline Number of job requirements (out of 12) & 7.36 & 7.40 & 7.39 \\
\hline Share of workers younger than 50 in occupation & $74.93 \%$ & $---\%$ & $---\%$ \\
\hline Share of workers in firms of fewer than 100 employees & 61.09 & 61.96 & 59.57 \\
\hline Job is highly automated & 14.78 & 14.62 & 14.96 \\
\hline Share with employer-sponsored insurance & 69.94 & 68.80 & 73.42 \\
\hline Average of the occupation's annual median earnings & $\$ 40,084.25$ & $\$ 38,558.16$ & $\$ 45,342.39$ \\
\hline Average of the occupation's median family income excluding own earnings & $26,672.46$ & $24,893.64$ & $32,100.59$ \\
\hline Share with no high school diploma/GED & $8.75 \%$ & $8.86 \%$ & $8.10 \%$ \\
\hline Share with high school diploma, GED, or some college & 45.72 & 46.38 & 42.26 \\
\hline Share with vocational, technical, or associate's degree & 15.83 & 15.62 & 16.51 \\
\hline Share with a college degree or more & 29.70 & 29.14 & 33.13 \\
\hline Share female & 46.65 & 46.63 & 48.50 \\
\hline Share married & 60.62 & 57.56 & 70.79 \\
\hline Share white or Asian, non-Hispanic & 75.01 & 72.71 & 81.59 \\
\hline Share Hispanic & 12.74 & 14.49 & 7.79 \\
\hline Share black non-Hispanic & 10.54 & 11.00 & 9.11 \\
\hline Share other race & 1.71 & 1.80 & 1.50 \\
\hline Number of occupation-years & 661 & 455 & 455 \\
\hline Number of unique occupations & 177 & 139 & 139 \\
\hline
\end{tabular}

Sources: Authors' calculations from the SIPP, 1996-2008 panels; the ORS, 2017; and the May O*Net Release, 2018. 
Table 3. Tobit Regression Estimates of the Relationship between Labor Market Outcomes and Share of Occupation with Health-Related Difficulties, 1997-2010

\begin{tabular}{ccc}
\hline & \multicolumn{2}{c}{ Share who in next 16 months... } \\
\cline { 2 - 3 } & Receive SSDI & $\begin{array}{c}\text { Leave job } \\
\text { for health reasons }\end{array}$ \\
\hline All workers & & \\
1+ difficulties & $0.0451^{* * *}$ & 0.0218 \\
& $(0.0163)$ & $(0.0175)$ \\
2+ difficulties & $0.0725^{* * *}$ & $0.0818^{* * *}$ \\
& $(0.0259)$ & $(0.0295)$ \\
3+ difficulties & 0.0495 & $0.1031^{* *}$ \\
& $(0.0359)$ & $(0.0464)$ \\
Workers ages 18-49 & & \\
1+ difficulties & 0.0218 & 0.0329 \\
& $(0.0195)$ & $(0.0217)$ \\
2+ difficulties & $0.0695^{*}$ & $0.0832^{* *}$ \\
& $(0.0356)$ & $(0.0423)$ \\
3+ difficulties & $0.0927^{*}$ & $0.1713^{* *}$ \\
& $(0.0511)$ & $(0.0727)$ \\
Workers ages 50-64 & & \\
1+ difficulties & $0.0991^{* * *}$ & 0.0377 \\
& $(0.0243)$ & $(0.0237)$ \\
2+ difficulties & $0.0962^{* *}$ & $0.0864^{* *}$ \\
& $(0.0379)$ & $(0.0395)$ \\
3+ difficulties & $0.1196^{* *}$ & $0.0947^{*}$ \\
& $(0.0507)$ & $(0.0535)$ \\
\hline
\end{tabular}

Notes: Each cell represents a separate regression of the labor market outcome on the index and a vector of occupational characteristics: a hazardous work environment index, the job's emphasis on high performance and problem-solving, workers' need for teamwork and emotional balance, the number of job requirements (out of 12), the share of workers younger than 50 in the occupation (not included in the age-specific regressions), the occupational tendency to operate on smaller scales, a job's tendency to be highly automated, the share covered by employer health insurance, the median occupational earnings (in $\$ 10,000$ ), the median family income in the occupation excluding the workers' own earnings (in $\$ 10,000$ ), the share of workers attaining various educational degrees, the share female, the share married, ethnicity shares within the occupation, and year fixed effects. Sample size is 661 occupation-years for the "all workers" analysis, and 455 occupation-years for the regressions by age. $* \mathrm{p}<0.10, * * \mathrm{p}<0.05, * * * \mathrm{p}<0.01$.

Sources: Authors' estimates from the SIPP, 1996-2008 panels; the ORS, 2017; and the May O*Net Release, 2018. 


\section{Appendix A}

Table A1. Full Tobit Marginal Effect Estimates for Share of the Occupation Receiving SSDI in the Next 16 Months, All Workers, 1997-2010

\begin{tabular}{|c|c|c|c|}
\hline & $(1)$ & $(2)$ & $(3)$ \\
\hline Health Mismatch Index (1+ difficulties) & $0.0451 * * *$ & - & \\
\hline Health Mismatch Index (2+ difficulties) & - & $0.0725 * * *$ & \\
\hline Health Mismatch Index (3+ difficulties) & - & - & 0.0495 \\
\hline O*NET hazardous work environments index & 0.0002 & 0.0002 & 0.0000 \\
\hline $\mathrm{O}^{*}$ NET high performance and problem-solving index & -0.0013 & -0.0012 & -0.0012 \\
\hline O*NET social skills index & 0.0012 & 0.0013 & 0.0012 \\
\hline Number of job requirements (out of 12) & $-0.0005^{*}$ & $-0.0005 *$ & -0.0002 \\
\hline Share of workers younger than 50 in occupation & $-0.0143 * * *$ & $-0.0153 * * *$ & $-0.0167 * * *$ \\
\hline Share of small workplaces (less than 100 employees) & $-0.0048 *$ & $-0.0057 * *$ & $-0.0065 * *$ \\
\hline Share of highly automated jobs & 0.0036 & 0.0041 & 0.0031 \\
\hline Share of workers with employer-sponsored insurance & $-0.0111 * * *$ & $-0.0120 * * *$ & $-0.0118 * * *$ \\
\hline Median occupation annual earnings (in $\$ 10,000$ ) & -0.0004 & -0.0004 & -0.0005 \\
\hline $\begin{array}{l}\text { Median family income excluding own earnings } \\
\text { (in } \$ 10,000 \text { ) }\end{array}$ & -0.0003 & -0.0005 & -0.0006 \\
\hline Share of workers with no high school diploma/GED & 0.0040 & 0.0047 & 0.0090 \\
\hline $\begin{array}{l}\text { Share of workers with a high school diploma, GED, or } \\
\text { some college schooling } \\
\text { Share of workers with a vocational, technical or }\end{array}$ & 0.0008 & 0.0017 & 0.0020 \\
\hline associate's degree & 0.0029 & 0.0027 & 0.0039 \\
\hline Share female & -0.0018 & -0.0010 & -0.0007 \\
\hline Share married & 0.0041 & 0.0049 & 0.0045 \\
\hline Share Hispanic & -0.0022 & -0.0035 & -0.0053 \\
\hline Share black non-Hispanic & -0.0015 & -0.0027 & -0.0011 \\
\hline Share other race & 0.0145 & 0.0150 & 0.0149 \\
\hline \multicolumn{4}{|l|}{ Year fixed effects } \\
\hline 1997 & -0.0004 & -0.0003 & 0.0000 \\
\hline 2002 & -0.0007 & -0.0004 & -0.0004 \\
\hline 2005 & $-0.0025 * * *$ & $-0.0024 * *$ & $-0.0022 * *$ \\
\hline Number of occupation-years & 661 & 661 & 661 \\
\hline
\end{tabular}

Note: $* \mathrm{p}<0.10, * * \mathrm{p}<0.05, * * * \mathrm{p}<0.01$.

Sources: Authors' estimates from the SIPP, 1996-2008 panels; the ORS, 2017; and the May O*Net Release, 2018. 
Table A2. Full Tobit Marginal Effect Estimates for the Share of the Occupation Leaving a Job for Health Reasons in the Next 16 Months, All Workers, 1997-2010

\begin{tabular}{lccc}
\hline & $(1)$ & $(2)$ & $(3)$ \\
\hline Health Mismatch Index (1+ difficulties) & 0.0218 & - & \\
Health Mismatch Index (2+ difficulties) & - & $0.0818^{* * *}$ & \\
Health Mismatch Index (3+ difficulties) & - & - & $0.1031^{* *}$ \\
O*NET hazardous work environments index & 0.0013 & 0.0015 & 0.0015 \\
O*NET high performance and problem-solving index & $-0.0018^{* *}$ & $-0.0017^{* *}$ & -0.0016 \\
O*NET social skills index & $0.0015^{*}$ & $0.0015^{*}$ & 0.0015 \\
Number of job requirements (out of 12) & 0.0004 & 0.0001 & 0.0002 \\
Share of workers younger than 50 in occupation & $-0.0177^{* *}$ & $-0.0163^{* *}$ & $-0.0172^{* *}$ \\
Share of small workplaces (less than 100 employees) & 0.0033 & 0.0034 & 0.0027 \\
Share of highly automated jobs & $-0.0096^{* *}$ & $-0.0083^{*}$ & $-0.0090^{* *}$ \\
Share of workers with employer-sponsored insurance & $-0.0081^{*}$ & $-0.0088^{*}$ & $-0.0087^{*}$ \\
Median occupation annual earnings (in \$10,000) & 0.0002 & 0.0002 & 0.0001 \\
Median family income excluding own earnings & & & \\
(in \$10,000) & $-0.0013^{*}$ & $-0.0013^{*}$ & $-0.0015^{* *}$ \\
Share of workers with no high school diploma/GED & 0.0116 & 0.0079 & 0.0111 \\
Share of workers with a high school diploma, GED, or & & & \\
some college schooling & 0.0022 & 0.0024 & 0.0028 \\
Share of workers with a vocational, technical or & & & \\
associate's degree & 0.0025 & 0.0011 & 0.0019 \\
Share female & $0.0060^{*}$ & $0.0063^{* *}$ & $0.0066^{* *}$ \\
Share married & -0.0101 & -0.0091 & -0.0090 \\
Share Hispanic & 0.0049 & 0.0048 & 0.0019 \\
Share black non-Hispanic & 0.0115 & 0.0091 & 0.0101 \\
Share other race & 0.0040 & 0.0019 & -0.0013 \\
Year fixed effects & & & \\
$\quad$ 1997 & 0.0025 & 0.0021 & 0.0021 \\
$\quad$ 2002 & $0.0048^{* * *}$ & $0.0048^{* * *}$ & $0.0047^{* * *}$ \\
$\quad$ 2005 & $0.0033^{* * *}$ & $0.0032^{* * *}$ & $0.0034^{* * *}$ \\
\hline Number of occupation-years & 661 & 661 & 661 \\
\hline
\end{tabular}

Note: $* \mathrm{p}<0.10, * * \mathrm{p}<0.05, * * * \mathrm{p}<0.01$.

Sources: Authors' estimates from the SIPP, 1996-2008 panels; the ORS, 2017; and the May O*Net Release, 2018. 


\section{Appendix B}

Results from the redesigned (and not comparable) 2014 SIPP panel. For the purposes of this analysis, the 2014 panel of the SIPP differs in two important ways: 1) core variables are collected only once per year, about the previous calendar year, so the recall window is much longer; and 2) health limitations are asked in the SSA supplement, which was conducted at a separate time from the core interviews. An additional problem is that, at the time of this analysis, the SIPP had released only one wave of the 2014 panel, covering calendar year 2013, but the SSA supplement was fielded nearly one year later, in late 2014. As a result, the analysis cannot ensure that people reporting health limitations were working at the time of the SSA supplement, or that they had the same occupation as they did in late 2013. Finally, an analysis of whether 2014 panel respondents subsequently leave their jobs for health reasons or receive SSDI will have to wait until after data is released for calendar year 2015, so that the respondents can be followed for a period after their health interview that would be comparable to earlier panels.

The following analysis, therefore, is presented separately from the main analysis, so that the reader does not include these results in the time series of how the Health Mismatch Index has changed since the 1990s. The lack of comparability is seen in the across-the-board increase in the Index in 2013, both overall (Table A3) and in each individual requirement (Figure A1). Over 11 percent of workers in 2013 report at least one difficulty with a required ability, nearly double the share reported in 2010.

Aside from their higher levels, other aspects of the 2013 results are similar to that of the pre-redesign SIPP survey years. Out of those who experienced some degree of health-job mismatch, it was most common to have difficulty with only 1 job requirement, with the rest spread about equally between 2 requirements and 3 or more requirements (see Table A3). Health-job mismatches again appeared at all ages, but about two-thirds of those who experienced difficulty in 2013 with at least one job requirement were ages 50-64, a share that was similar to earlier SIPP years. ${ }^{18}$ When looking at job requirements that were the greatest source of difficulty for 2013 respondents, standing for one hour, hearing in conversational settings, and lifting $25 \mathrm{lbs}$. were still the ones most frequently reported (see Figure A1).

\footnotetext{
${ }^{18}$ Specifically, the share is 67.3 percent in 2013. In 1997, 2002, 2005 and 2010, the shares were 71 percent, 69 percent, 70.4 percent, and 69.9 percent, respectively.
} 
Many occupations that made the top 15 mismatch list for the earlier SIPP years were still found in the 2013 rankings, including occupations from the health care, education, food service, and custodial sectors. New arrivals on the 2013 list were predominantly from blue collar occupations, such as industrial machinery mechanics, maintenance and repair workers, stock clerks and order fillers, and painters (see Tables A4a and A4b).

Despite some similarities to earlier panels, the 2013 results should be taken with a grain of salt. The 2013 results do not allow for evaluating whether the trend toward decreasing healthrelated mismatch continued; nor should one interpret the higher levels as definitive evidence that the trend reversed, given the SIPP redesign and the difference in the timing of the interview questions. Furthermore, the 2013 panel does not yet include information on whether workers from occupations with high Health Mismatch Index values were, as in prior panels, more likely to subsequently leave their jobs for health reasons or receive SSDI. 
Figure B1. Share of U.S. Workforce Experiencing Each Specific Difficulty, by Year

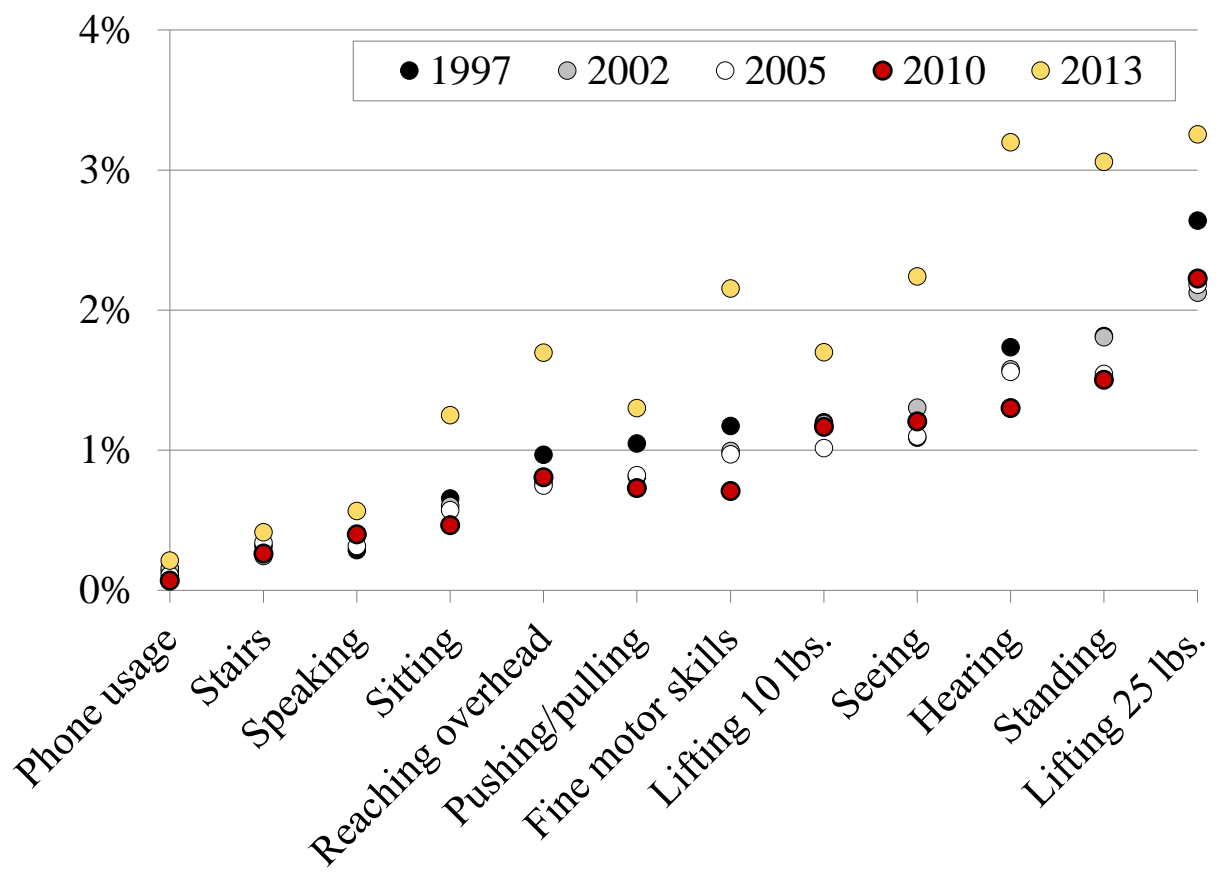

Sources: Authors' calculations from the SIPP, 1996-2014 panels; and the ORS, 2017. 
Table B1. Percent of U.S. Workforce Experiencing Difficulty with Health-Related Job Requirements, 2013

\begin{tabular}{lcccc}
\hline & $\begin{array}{c}1 \\
\text { requirement }\end{array}$ & $\begin{array}{c}2 \\
\text { requirements }\end{array}$ & $\begin{array}{c}3+ \\
\text { requirements }\end{array}$ & $\begin{array}{c}1+ \\
\text { requirements }\end{array}$ \\
\hline Age $<50$ & $4.8 \%$ & $2.0 \%$ & $1.3 \%$ & $8.1 \%$ \\
Age 50+ & 9.3 & 3.9 & 3.4 & 16.7 \\
\hline Overall & 6.6 & 2.7 & 2.1 & 11.4 \\
\hline
\end{tabular}

Sources: Authors' calculations from the SIPP, 2014 panel; and the ORS, 2017. 
Table B2a. Top 15 Occupations with the Highest Share of Workers with 1+ Difficulty with Health-Related Job Requirements, 2013

\begin{tabular}{llc}
\hline Rank & Occupation & Share with 1+ difficulty \\
\hline 1 & Teacher assistants & $30.5 \%$ \\
2 & Bartenders & 26.1 \\
3 & Insurance claims and policy processing clerks & 25.5 \\
4 & Maintenance and repair workers, general & 23.8 \\
5 & Stock clerks and order fillers & 23.7 \\
6 & Billing and posting clerks & 23.0 \\
7 & First-line supervisors of housekeeping and janitorial workers & 23.0 \\
8 & Nursing, psychiatric, and home health aides & 22.4 \\
9 & Assemblers and fabricators, all other & 22.3 \\
10 & Personal care aides & 22.1 \\
11 & Bus drivers & 21.5 \\
12 & Maids and housekeeping cleaners & 21.5 \\
13 & Cooks & 21.4 \\
14 & Industrial machinery mechanics & 20.9 \\
15 & Painters, construction, and maintenance & 20.8 \\
\hline
\end{tabular}

Table B2b. Top 15 Occupations with the Highest Share of Workers with 2+ Difficulties with Health-Related Job Requirements, 2013

\begin{tabular}{llc}
\hline Rank & Occupation & Share with 2+ difficulties \\
\hline 1 & Bartenders & $20.8 \%$ \\
2 & Bakers and food batchmakers & 15.9 \\
3 & Stock clerks and order fillers & 15.2 \\
4 & Personal care aides & 14.7 \\
5 & Teacher assistants & 14.3 \\
6 & Maintenance and repair workers, general & 13.4 \\
7 & Bus drivers & 13.2 \\
8 & Licensed practical and licensed vocational nurses & 13.0 \\
9 & Cashiers & 12.5 \\
10 & Hairdressers, hairstylists, and cosmetologists & 12.2 \\
11 & Human resources managers & 11.9 \\
12 & Maids and housekeeping cleaners & 11.9 \\
13 & Assemblers and fabricators, all other & 11.3 \\
14 & First-line supervisors of housekeeping and janitorial workers & 11.2 \\
15 & Installation, maintenance, and repair workers, all other & 10.8 \\
\hline
\end{tabular}

Sources: Authors' calculations from the SIPP, 2014 panel; and the ORS, 2017. 


\section{RECENT WORKING PAPERS FROM THE CENTER FOR RETIREMENT RESEARCH AT BOSTON COLLEGE}

How Does Contingent Work Affect SSDI Benefits?

Matthew S. Rutledge, Alice Zulkarnain, and Sara Ellen King, February 2019

Do Pension Cuts for Current Employees Increase Separation?

Laura D. Quinby and Gal Wettstein, January 2019

Competition, Asymmetric Information, and the Annuity Puzzle: Evidence from a Government-Run Exchange in Chile

Gastón Illanes and Manisha Padi, January 2019

Failure to Contribute: An Estimate of the Consequences of Non- and Underpayment of Self-Employment Taxes by Independent Contractors and On-Demand Workers on Social Security

Caroline Bruckner and Thomas L. Hungerford, January 2019

How Much Income Do Retirees Actually Have? Evaluating the Evidence from Five National Datasets

Anqi Chen, Alicia H. Munnell, and Geoffrey T. Sanzenbacher, November 2018

The Minimum Wage and Incentives for Full-Time Work Under the Social Security Retirement Earnings Test

Gary V. Engelhardt, October 2018

Would Greater Awareness of Social Security Survivor Benefits Affect Claiming Decisions? Anek Belbase and Laura D. Quinby, October 2018

How Does Delayed Retirement Affect Mortality and Health?

Alice Zulkarnain and Matthew S. Rutledge, October 2018

How Have Automation and Trade Affected the Taxable Share of Covered Earnings? Gal Wettstein, Matthew S. Rutledge, and Wenliang Hou, October 2018

Spillovers from State and Local Pensions to Social Security: Do Benefits for Uncovered Workers Meet Federal Standards?

Laura D. Quinby, Jean-Pierre Aubry, and Alicia H. Munnell, September 2018

Accounting for Social Security Claiming Behavior

Svetlana Pashchenko and Ponpoje Porapakkarm, September 2018

All working papers are available on the Center for Retirement Research website (http://crr.bc.edu) and can be requested by e-mail (crr@bc.edu) or phone (617-552-1762). 